GRANGEIRO, L.C.; PEDROSA, J.F.; BEZERRA NETO, F.; NEGREIROS, M.Z.de. Rendimento de híbridos de melão amarelo em diferentes densidades de plantio. Horticultura Brasileira, Brasília, v. 17, n. 3, p.200-206, novembro 1999.

\title{
Rendimento de híbridos de melão amarelo em diferentes densidades de plantio.
}

\section{Leilson Costa Grangeiro; Josué Fernandes Pedrosa; Francisco Bezerra Neto; Maria Z. de Negreiros} ESAM - Depto. de Fitotecnia, C. Postal 137, 59.625-900 Mossoró - RN.

\begin{abstract}
RESUMO
Este trabalho teve como objetivo avaliar o rendimento de híbridos de melão amarelo em diferentes densidades de plantio. Para tanto, conduziu-se um experimento na Fazenda Santa Júlia Agro Comercial Exportadora de Frutas Tropicais Ltda., no município de Mossoró RN. O delineamento experimental foi o de blocos casualizados em esquema fatorial $3 \times 4$, com quatro repetições, sendo o primeiro fator, os híbridos (Gold Mine, AF 646 e XPH 13096) e o segundo as densidades de plantio (10.000, 20.000, 30.000 e 40.000 plantas/ha). As características avaliadas foram, número de frutos por planta e total, peso médio dos frutos, produtividade e classificação dos frutos. O número de frutos por planta e o peso médio dos frutos diminuíram com o aumento da densidade de plantio, sendo que os híbridos XPH 13096 e AF 646 apresentaram os maiores decréscimos 70,16\% e $27,60 \%$ respectivamente. A densidade de 30.000 plantas/ha, proporcionou a maior produtividade $(61,75 \mathrm{t} / \mathrm{ha})$. A percentagem de frutos tipo 5, 6 e 7, diminuíram com o aumento da densidade de plantio, enquanto os outros tipos aumentaram, sendo o híbrido AF 646 o que apresentou maior percentagem de decréscimo. O híbrido AF 646 foi superior aos demais, para o número total de frutos e produtividade.
\end{abstract}

Palavras-chave: Cucumis melo, população de plantas, produtividade, peso médio de frutos.

\section{ABSTRACT}

Yield of yellow melon hybrids in different plant densities.

The purpose of this work was to evaluate the yield of fruits in hybrids of yellow melon. The experiment was carried out at the $\mathrm{Fa}$ zenda Santa Júlia Agro Comercial Exportadora de Frutas Tropicais Ltda. The experimental design was a complete randomised block, with four replicates, in a $3 \times 4$ factorial scheme, with the following factors: hybrids (Gold Mine, AF 646 and XPH 13096) and plant density $(10,000 ; 20,000 ; 30,000$ and 40,000 plants/ha). Fruit classification, total number of fruits and total per plant, mean fruit weight and yield were evaluated. Total number of fruits and total per plant, mean fruit weight and yield were reduced with increasing plant density. The hybrids XPH 13096 and AF 646 showed the greatest reductions in the number of fruits per plant and in the mean fruit weight, 70.16 and $27.60 \%$, respectively. The density of 30,000 plants/ha provided the greatest productivity $(61.75 \mathrm{t} / \mathrm{ha})$. The increase in the plant density produced less fruits of categories 5, 6, and 7, particularly for hybrid AF 646, while number of fruits for other categories increased. The hybrid AF 646 showed the highest total number of fruits and yield.

Keywords: Cucumis melo, plant population, yield, mean fruit weight.

(Aceito para publicação em 10 de agosto de 1999)

$\mathrm{O}$ Brasil é, atualmente, o terceiro produtor de melão da América do Sul, depois da Argentina e do Chile, com $17 \%$ da produção total. A região Nordeste responde por mais de $91 \%$ da pro- dução total do país (ANUÁRIO... 1987/ 1994). O Estado do Rio Grande do Norte, é o maior produtor brasileiro, destacando-se, em 1996, com 56,12\% da área plantada e 63,36\% da produção.
Aproximadamente $98 \%$ do melão produzido no Brasil pertence ao grupo "Amarelo" (inodorus) do qual fazem parte diversas cultivares e híbridos. Os outros $2 \%$ pertencem aos melões das 
variedades cantalupensis e reticulatus, que apesar de possuírem alto valor comercial, principalmente no mercado externo, têm cultivo ainda muito restrito devido à limitada resistência dos frutos ao transporte e à má conservação pós-colheita.

No polo agrícola Mossoró - Açu (RN), essa espécie olerícola é cultivada com alto nível tecnológico e sua exploração é feita, atualmente, tanto por grandes empresas quanto também por pequenos agricultores, predominando o cultivo de melões tipo Amarelo. Entretanto, com a abertura de novos mercados, principalmente as grandes empresas, têm procurado diversificar e ampliar sua produção, através da introdução de novas cultivares e híbridos. Essas introduções têm sido feitas, na maioria das vezes de forma precipitada, e tem proporcionado em alguns casos, prejuízos para os produtores. Nem sempre uma nova cultivar está adaptada às condições de cultivo da região, refletindo em menor produtividade, frutos de qualidade inferior, e algumas vezes de menor aceitação pelo consumidor.

Nesse contexto, o estudo de fatores de produção, tais como, adubação, irrigação, densidade de plantio e outras práticas culturais, torna-se necessário para esses novos materiais. No caso especifico da densidade de plantio, tem sido verificado em diversos trabalhos que os resultados variam de acordo com as cultivares e híbridos e também com as regiões produtoras.

Paris et al. (1988), utilizando populações de 5.000 a 40.000 plantas/ha com melão Galia, obtiveram decréscimo no tamanho e no número de frutos por planta com o aumento da densidade. Os mesmos resultados foram obtidos por Mendlinger (1994), trabalhando também com melão Galia, nas densidades de 20, 40 e 80 mil plantas por hectare, porém ocorrendo aumento no número total de frutos. Resultados similares foram encontrados por Knavel (1988), Farias et al. (1988) e Scharles \& Timothy (1988).

A modificação na densidade de plantio, por meio do aumento do número de plantas por cova, também proporcionou ganhos de produtividade em melão, segundo Costa et al. (1996), trabalhando com o espaçamento 1,8 x $0,20 \mathrm{~m}$, cv.
Valenciano Amarelo, observaram aumento na produtividade quando utilizaram duas plantas/cova, enquanto que no tratamento com uma planta/cova houve aumento no peso médio dos frutos. Pedrosa et al. (1991), utilizando também uma e duas plantas por cova, mas no espaçamento 2,0 x 0,6m, não encontraram efeito significativo dos tratamentos sobre a produção total e comerciável, entretanto o cultivo com uma planta por cova apresentou frutos de maior diâmetro longitudinal, aumentou em $87 \%$ o número e em $20 \%$ o peso médio de frutos comerciáveis.

Segundo Pedrosa (1997), a densidade de plantio em melão, varia em função do nível tecnológico empregado e da finalidade do produto (fruto para o mercado interno ou externo), sendo que no Rio Grande do Norte, o espaçamento adotado pelos produtores, segundo Almeida (1992), é de 2,0 a 2,5m entre fileiras e 0,3 a $1,0 \mathrm{~m}$ entre plantas, deixando 1 ou 2 plantas por cova (4.000 a 30.000 plantas/ha). Atualmente o espaçamento mais utilizado, principalmente pelas grandes empresas, tem sido $2,0 \times 0,5 \mathrm{~m}$ com duas ou três plantas por cova (20.000 a 30.000 plantas/ha).

Com relação às regiões produtoras, o melão pode responder diferentemente ao aumento das densidades de plantio, dependendo das condições edafoclimáticas em que está sendo cultivado. Paris et al. (1988), conduziram experimentos em Israel e na Flórida (EUA), e obtiveram com o aumento da densidade de plantio uma queda no peso médio de frutos em ambos os locais, porém o número e a produção não foram afetados pela densidade na Flórida, mas teve um aumento significativo em Israel. Os autores citam ainda, que ocorreu uma elevação na concentração do número de frutos e no total da produção durante o período de colheita com o incremento da densidade, em Israel.

O presente trabalho teve como objetivo avaliar o rendimento de híbridos de melão amarelo, cultivados em quatro densidades de plantio.

\section{MATERIAL E MÉTODOS}

O experimento foi conduzido na Fazenda Santa Júlia Agro Comercial
Exportadora de Frutas Tropicais Ltda., em Mossoró, em solo Podzólico Vermelho-Amarelo Eutrófico, textura arenosa. As análises químicas, feitas em amostras retiradas da área experimental, revelaram os seguintes resultados: $\mathrm{pH}($ água $1: 2,5)=5,2 ; \mathrm{Ca}=1,0 \mathrm{cmol} /$ $\mathrm{kg} ; \mathrm{Mg}=0,2 \mathrm{cmol} / \mathrm{kg} ; \mathrm{K}=0,28 \mathrm{cmol} /$ $\mathrm{kg} ; \mathrm{Al}=0,10 \mathrm{cmol} / \mathrm{kg}$ e $\mathrm{P}=28 \mathrm{mg} / \mathrm{kg}$. $\mathrm{O}$ preparo do solo constou de uma aração e duas gradagens, seguidas do sulcamento em linhas, espaçadas de dois metros com profundidade de aproximadamente $0,2 \mathrm{~m}$, onde foi realizada a adubação de base, com 10 t/ha de esterco bovino curtido, $500 \mathrm{~kg} / \mathrm{ha}$ da fórmula 6 $24-12,150 \mathrm{~kg} / \mathrm{ha}$ de superfosfato simples e $100 \mathrm{~kg} / \mathrm{ha}$ de calcário dolomítico.

O plantio foi realizado no dia 1 de outubro de 1996, sendo que após a germinação o estande foi completado com mudas produzidas em bandejas.

As adubações de cobertura foram realizadas via água de irrigação, com aplicação diária de $2,91 \mathrm{~kg}$ de N/ha e $4,9 \mathrm{~kg}$ de $\mathrm{K} \mathrm{O} / \mathrm{ha}$, na concentração de $228 \mathrm{~g} / \mathrm{L}$, da germinação até os 45 e 60 dias após esta, respectivamente. As fontes de nitrogênio utilizadas foram uréia e nitrato de amônio e a de potássio foi o cloreto de potássio. Seguida a cada adubação, injetou-se no sistema de irrigação $1,5 \mathrm{~L} / \mathrm{ha}$ de ácido fosfórico, com o objetivo de limpar a tubulação e evitar a obstrução dos gotejadores. Essa injeção permitiu um fornecimento total de $72 \mathrm{~kg} /$ ha de $\mathrm{P}_{2} \mathrm{O}_{5}$. As adubações foram complementadas com aplicações foliares semanais, da germinação até os 60 dias após esta, de $3 \mathrm{~L} / \mathrm{ha}$ da formulação comercial líquida, contendo $8 \%$ de cálcio e $2 \%$ de boro e, $2,5 \mathrm{~L} / \mathrm{ha}$ da formulação comercial líquida, contendo $14 \%$ de $\mathrm{N} ; 4 \%$ de $\mathrm{P}_{2} \mathrm{O}_{5} ; 6 \%$ de $\mathrm{K}_{2} \mathrm{O}$; $0,8 \%$ de $\mathrm{S} ; 1,5 \%$ de $\mathrm{Mg} ; 2 \%$ de $\mathrm{Zn} ; 1,5 \%$ de $\mathrm{Mn} ; 0,1 \%$ de B e $0,05 \%$ de Mo.

O controle fitossanitário foi realizado preventivamente e os demais tratos culturais de acordo com as necessidades da cultura.

O delineamento experimental utilizado foi o de blocos casualizados completos, em esquema fatorial $3 \times 4$, com quatro repetições, sendo que o primeiro fator refere-se aos híbridos (Gold Mine, AF 646 e XPH 13096) e o segundo, às densidades de plantio $(1,2,3$ e 4 plan- 


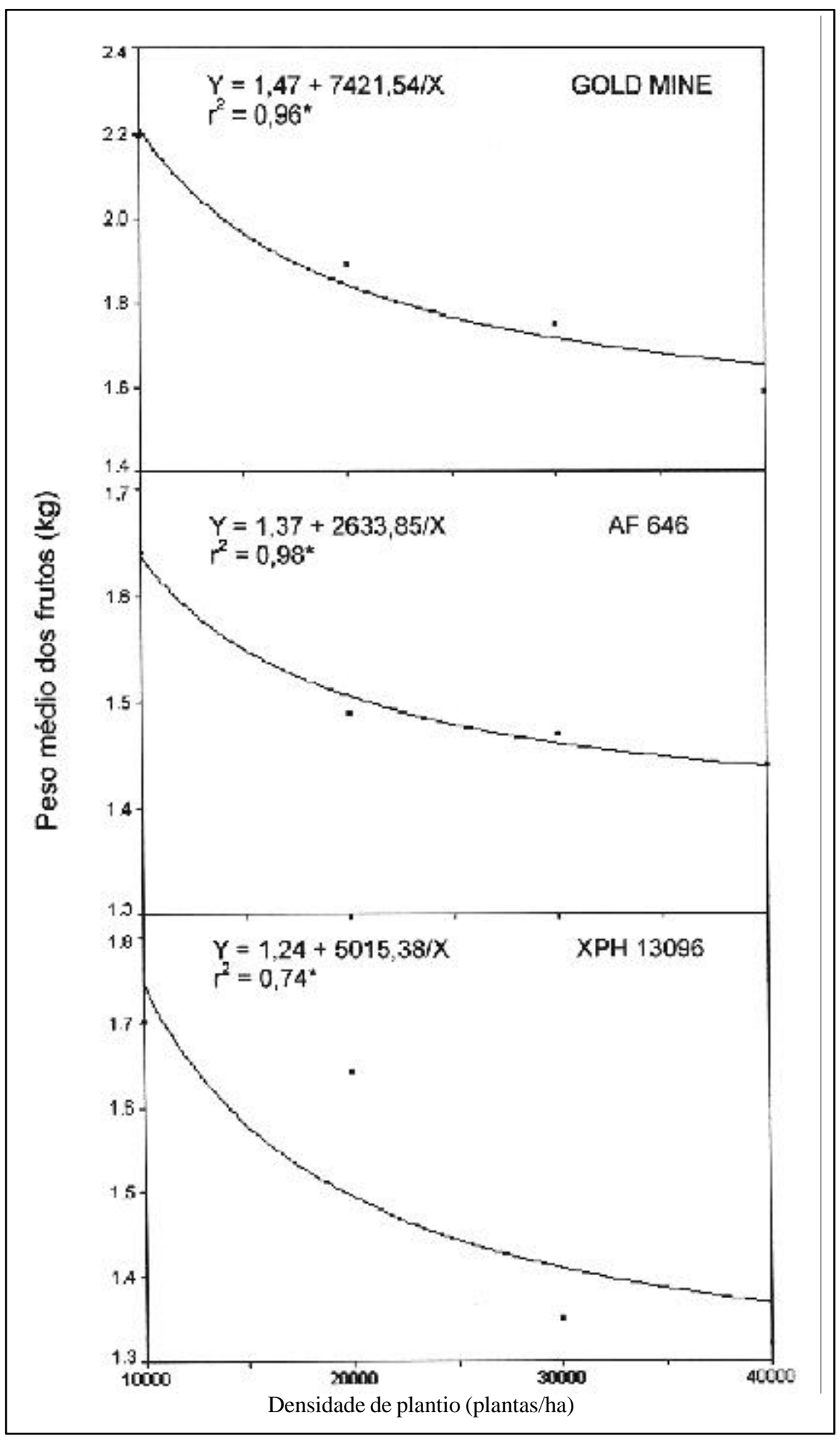

Figura 1. Peso médio dos frutos em função das diferentes densidades de plantio para os híbridos de melão Gold Mine, AF 646 e XPH 13096. Mossoró (RN), ESAM, 1996.

tas/gotejador, correspondendo às populações de 10.000, 20.000, 30.000 e 40.000 plantas/ha). Cada parcela era composta por uma fileira de cinco metros de comprimento, contendo dez gotejadores, com distanciamento de 2,0 $\mathrm{m} \times 0,5 \mathrm{~m}$, sendo que os das extremida- des eram considerados como bordadura, ficando com uma área útil de $8 \mathrm{~m}$. Entre os blocos foi deixada uma fileira de plantas como bordadura.

As colheitas foram realizadas aos 62 , 69 e 76 dias após a semeadura, sendo a primeira no dia 2 de dezembro de 1996.
O critério para colheita adotado foi a coloração do fruto, ou seja, quando os mesmos apresentavam-se totalmente amarelos.

As características avaliadas foram: peso médio dos frutos $(\mathrm{kg})$, número de frutos por planta, número total de frutos por hectare, classificação dos frutos, realizada de acordo com o tipo (5 a 12 frutos por caixa), padronizados pela empresa para mercado interno, em caixa de papelão ( 52 × 32 x 17,5 cm ) com capacidade para $13 \mathrm{~kg}$ e produtividade ( $\mathrm{t} / \mathrm{ha}$ ).

As análises de variância foram realizadas através do software SPSSPC (Norusis, 1990). Para o fator quantitativo foi feito análise de regressão através do software Table Curve (Jandel Scientific, 1991), enquanto que para o fator qualitativo foi utilizado o teste Tukey ao nível de 5\% de probabilidade (Gomes, 1987).

\section{RESULTADOS E DISCUSSÃO}

Dentre as características avaliadas, apenas verificou-se efeito significativo da interação densidade de plantio e híbridos, para número de frutos por planta e peso médio de frutos.

\section{Peso médio dos frutos}

Observa-se que à medida que aumentou a densidade de plantio houve redução no peso médio dos frutos, em todos os híbridos (Figura 1). Entretanto o maior decréscimo foi registrado para o híbrido Gold Mine $(27,60 \%)$ e o menor para o AF 646 (12,0\%). Para essa mesma variação de densidade, Mendlinger (1994) obteve redução de $18,85 \%$ no peso médio dos frutos de melão Galia. Pedrosa et al. (1991), detectaram redução de $20 \%$, quando utilizaram duas plantas por cova na cultivar Valenciano Amarelo. Reduções também foram observadas por Brinen et al. (1979), Paris et al. (1988) e Powell et al. (1993).

Nessa redução, apesar de ter sido expressiva, mesmo na densidade de 40.000 plantas/ha, os híbridos apresentaram peso médio dos frutos, variando de 1,3 a $1,6 \mathrm{~kg}$, sendo comercialmente desejável para o consumidor.

Robinson \& Decker-Walteres (1997), relatam que a redução no peso médio dos frutos em altas densidades de 
plantio é esperada, pois os recursos do solo (água e nutrientes) são insuficientes, devida à competição entre as plantas. Em estádios mais avançados de desenvolvimento, a sobreposição das folhas, induz à reduzida taxa fotossintética líquida, prejudicando todo o processo de assimilação e distribuição dos fotoassimilados.

\section{Número de frutos por planta}

$\mathrm{O}$ número de frutos por planta decresceu com o aumento da densidade de plantio em todos os híbridos estudados, sendo registrado o maior decréscimo para o híbrido XPH 13096 (em torno de $70,16 \%$ ) e o menor para o 'Gold Mine' (em torno de 55,32\%) (Figura 2). Esses resultados concordam com os encontrados por Paris et al. (1988) e Mendlinger (1994) para melão, Patil \& Bhosale (1979), Brinen et al. (1979), Gramberry et al. (1986), Nesmith (1993) para melancia, e por Cantliffe \& Phatak (1975) e O'Sullivan (1980) para pepino.

Observa-se que o 'Gold Mine' foi o que apresentou menor decréscimo no número de frutos por planta com o aumento da densidade, indicando ser menos susceptível às pressões de competições entre as plantas, com relação à diminuição do rendimento individual por planta.

Geralmente espera-se a obtenção de menor número de frutos por planta, com o aumento da densidade de plantio, em consequiência do menor espaço disponível às plantas, que favorece maior competição por elementos do solo e luz, diminuindo com isso, a atividade fotossintética, produção de ramos, folhas, flores, frutos e o trabalho das abelhas no processo de polinização.

\section{Número total de frutos}

Para o número total de frutos, verificou-se efeito significativo para a densidade de plantio e híbridos. Inversamente ao número de frutos por planta, foi observado com o aumento da densidade de plantio maior número de frutos por hectare. Esse acréscimo foi de aproximadamente $28,57 \%$, equivalente a um incremento de 11.746 frutos/ha (Figura 3). Sendo, segundo Nesmith (1993), o componente que mais contribui para o aumento da produtividade.

Esses resultados estão aquém dos

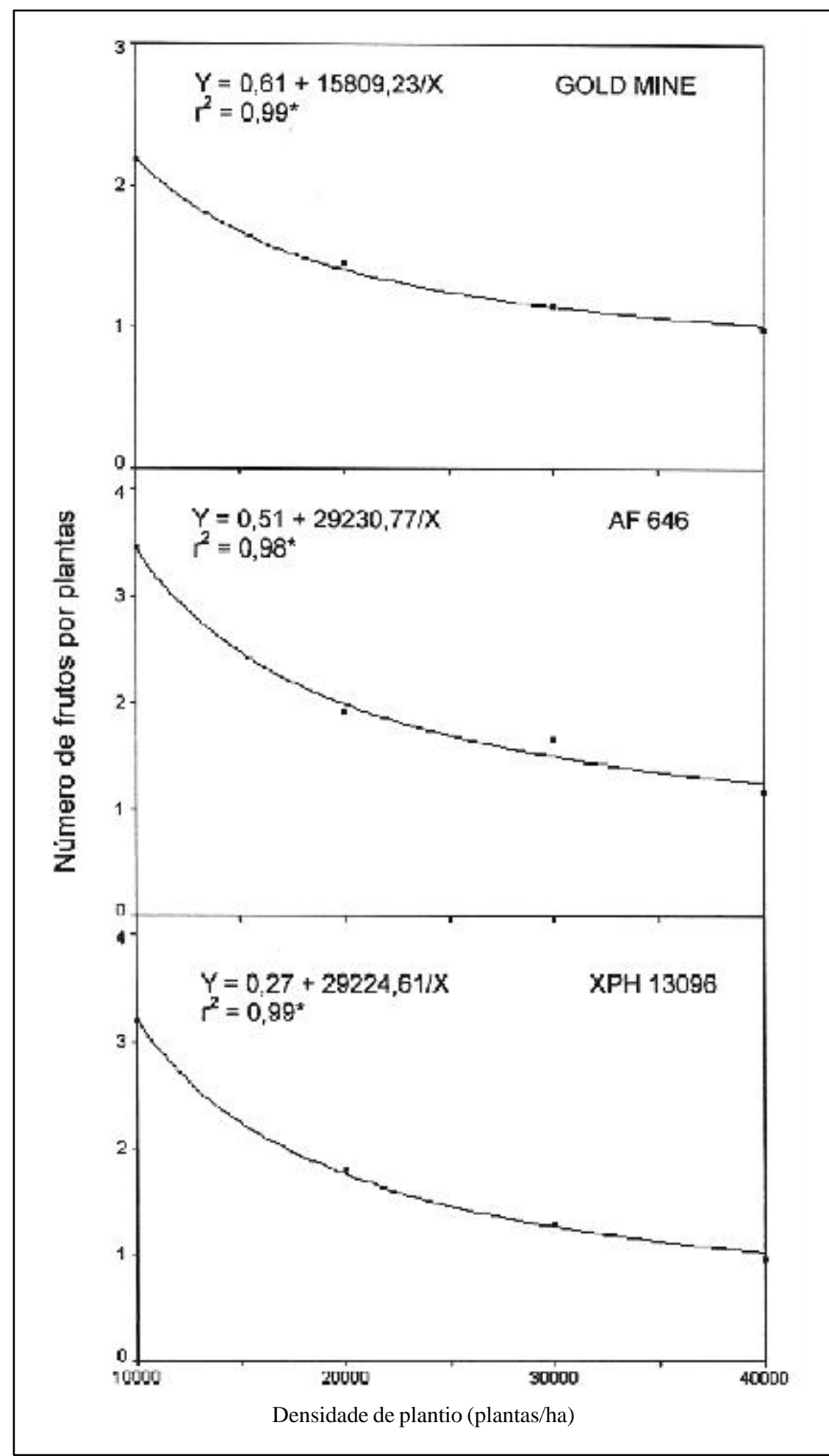

Figura 2. Número de frutos por planta em função das diferentes densidades de plantio para os híbridos de melão Gold Mine, AF 646 e XPH 13096. Mossoró (RN), ESAM, 1996.

encontrados por Paris et al. (1988) que obtiveram aumentos de $158 \%$ e $80 \%$ respectivamente no número total de frutos, em melão Galia e híbrido D-72, quando variou a população de 5.000 para 40.000 plantas/ha. Para Mendlinger (1994), a percentagem foi de $24,43 \%$ na população de 10.000 a 40.000 planta/ ha. Com relação aos híbridos, o AF 646 foi o que apresentou maior número to- 


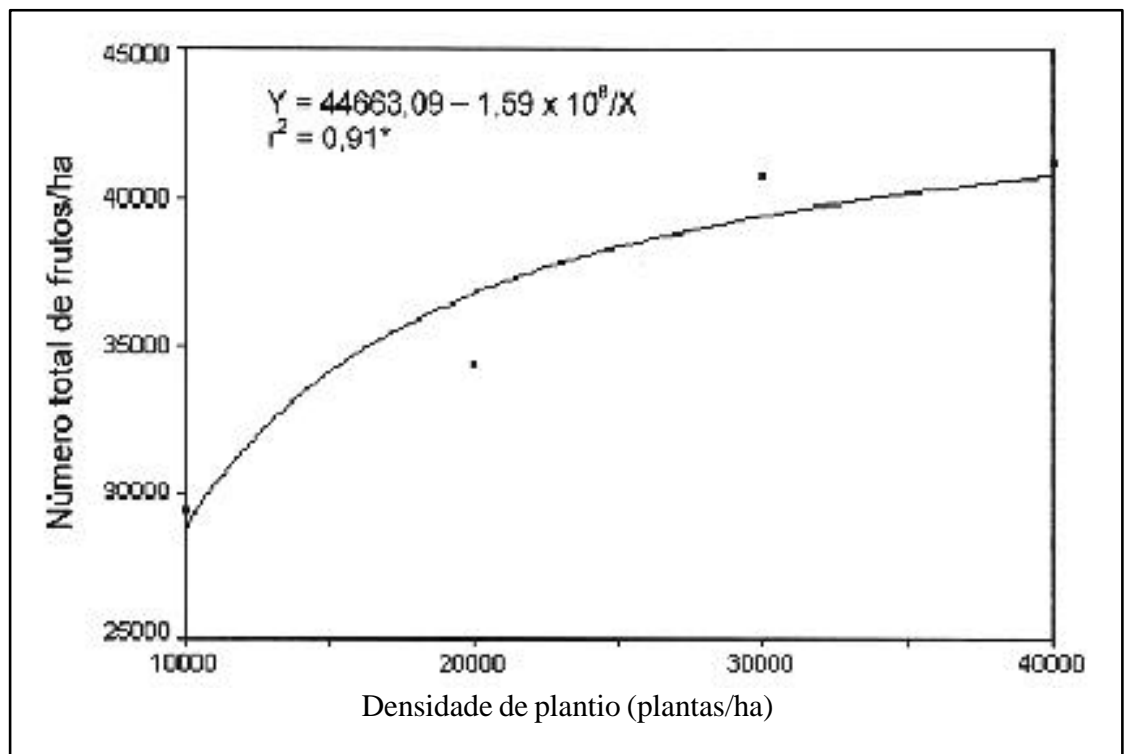

Figura 3. Número total de frutos por hectare em função das diferentes densidades de plantio de melão. Mossoró (RN), ESAM, 1996.

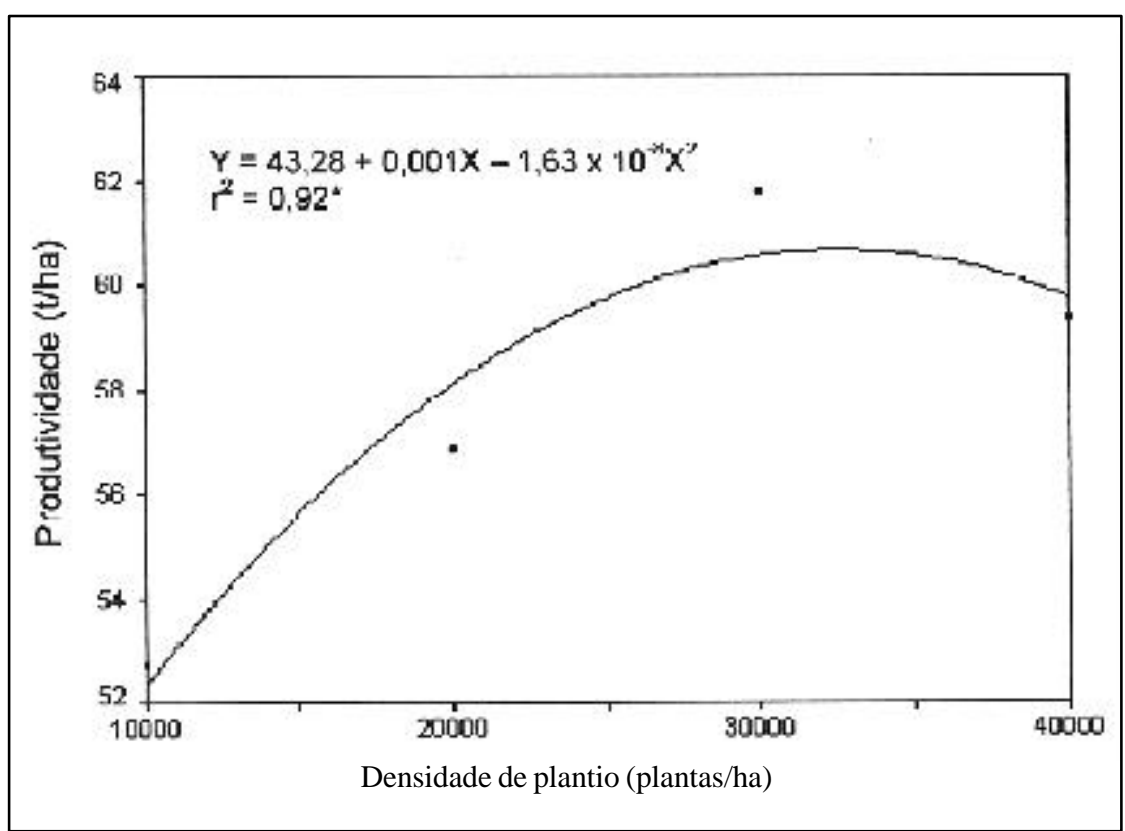

Figura 4. Produtividade de frutos de melão em função das diferentes densidades de plantio de melão. Mossoró - RN, ESAM, 1996.

tal de frutos, seguidos pelo 'XPH 13096' e 'Gold Mine' (Tabela 1).

\section{Produtividade}

Para a produtividade, observou-se que híbridos e densidade de plantio apresentaram efeito significativo. A medida que se aumentou a densidade de plantio, houve aumento na produtividade, até a população de 32.584 plantas/ha (Figura 4). Esses resultados corroboram com os obtidos por Paris et al. (1988) e
Mendlinger (1994) em melão Galia. Nesses trabalhos a densidade de 20.000 plantas/ha foi a que proporcionou maior produtividade, sendo que a partir desta, houve reduções significativas no rendimento da cultura.

Os resultados obtidos, à semelhança dos citados por Blesdale (1969), Holliday (1969) e Willey \& Heath (1969), refletem o efeito da densidade de plantio no rendimento. Segundo es- ses autores, o rendimento é crescente até uma determinada população; a partir desta há um decréscimo na produtividade à medida que se aumenta a população. Isto ocorre em função da competição excessiva que se estabelece entre as plantas, principalmente com relação à radiação solar devido ao aumento do índice de área foliar. Este índice incrementa com o desenvolvimento da planta e com o número de planta na área, e varia em função da cultivar e híbrido, época do ano e das condições climáticas.

$\mathrm{O}$ incremento observado pode ser expressivo, quando se compara o aumento da população de 10.000 para 30.000 plantas/ha, em torno de $15 \%$, equivalente a um ganho de 9,04 t/ha.

A maior produtividade foi obtida para o híbrido AF 646 (Tabela 1), sendo superior em $10,56 \%$ e $14,75 \%$ respectivamente ao 'Gold Mine e 'XPH 13096'. Este fato se deve principalmente, ao maior número total de frutos produzidos pelo o AF 646, mesmo com peso médio menor.

Outro aspecto também analisado, foi a concentração de frutos nas respectivas colheitas (Tabela 2). Verificou-se que o aumento da densidade de plantio não interferiu nesta característica, discordando dos resultados observado por Paris et al. (1988) em melão 'Galia' e híbrido D 72, Cantliffe \& Phatak (1975), Paris et al. (1986) em pepino, que obtiveram concentrações maiores no número de frutos nas primeiras colheitas quando aumentaram a densidade de plantio.

Embora não tenha havido diferença significativa entre híbridos, em média, $63,61 \%$ dos frutos foram obtidos na primeira colheita, com uma superioridade do 'AF 646' (70,52\%) sobre os demais (Tabela 2). Em alguns híbridos tem se observado que em cultura bem conduzida, a colheita chega a se estender por cerca de um mês (4 a 5 colheitas a intervalos de uma semana). A concentração da produção em menor número de colheitas possíveis, é fator desejável, principalmente do ponto de vista econômico, pois reduz custos com insumos, água, energia e mão de obra para as colheitas adicionais.

\section{Classificação dos frutos}

Um dos principais fatores que influencia na boa comercialização é a classificação do produto, que por sua vez, 
depende do controle de qualidade. É altamente benéfico ao produtor, pela disponibilidade de mercado mais amplo, e ao consumidor, pela opção de compra e garantia de qualidade.

Verifica-se que com o aumento da densidade de plantio, houve de uma maneira geral, redução na percentagem de frutos dos tipos 5, 6 e 7 para todos os híbridos, e aumento de frutos menores (tipos 8 a 12). Essa redução foi, respectivamente, para o 'Gold Mine', 'XPH
13096' e 'AF 646' de 36,0\%, 44,59\% e $58,68 \%$ (Tabela 3). Davis \& Meinert (1965) e Mendlinger (1994), obtiveram também maior quantidade de frutos de categorias menores, quando aumentaram a densidade de plantio de melão.

Os frutos que não se enquadraram nessa classificação, foram considerados a granel, sendo os mesmos comercializados em feiras livres e supermercados locais. Nas maiores densidades de plantio, a percentagem desse

Tabela 1. Número total de frutos (x1000) e produtividade (t/ha) para os híbridos Gold Mine, AF 646 e XPH 13096. Mossoró (RN), ESAM, 1996.

\begin{tabular}{|c|c|c|}
\hline Híbridos & Número total de frutos/ha (x 1000) & Produtividade (t/ha) \\
\hline Gold Mine & 31,10 & $56,32 A B$ \\
\hline AF 646 & $42,00 \mathrm{~A}$ & $62,98 \mathrm{~A}$ \\
\hline XPH 13096 & $35,95 \quad B$ & $53,69 \quad B$ \\
\hline CV $(\%)$ & 14,23 & 17,24 \\
\hline $\begin{array}{l}{ }^{1} \text { Médias na verti } \\
\text { Tukey. }\end{array}$ & I seguidas da mesma letra não diferem entre s & si $(\mathrm{p}<0,05)$ pelo teste de \\
\hline $\begin{array}{l}\text { Tabela 2. Percen } \\
646 \text { e XPH } 13096\end{array}$ & $\begin{array}{l}\text { m de frutos nas diferentes colheitas para os } 1 \\
\text { ssoró (RN), ESAM, } 1996 .\end{array}$ & híbridos Gold Mine, AF \\
\hline Híbridos & 1a Colheita (\%) 2a Colheita (\%) & 3a Colheita (\%) \\
\hline Gold Mine & 31,93 & 9,40 \\
\hline AF 646 & 22,43 & 7,05 \\
\hline XPH 13096 & 61,64 & 8,71 \\
\hline MÉDIA & 28,00 & 8,39 \\
\hline
\end{tabular}

tipo de fruto aumentou para todos os híbridos, com destaque para o ' $\mathrm{XPH}$ 13096'. O'Sullivan (1980) e Paris et al. (1986), verificaram maior quantidade de frutos refugos, quando aumentaram a densidade de plantio em pepino e Brinen et al. (1979) em melancia. Segundo os autores, isso pode ser atribuído à grande competição entre plantas por luz e nutrientes.

Em termos econômicos, estes resultados são de grande importância para o agricultor, haja visto que, dependendo do mercado e da variação de preços, a modificação da densidade de plantio pode ser utilizada, como uma ferramenta para se conseguir maiores lucros, sem maiores despesas.

\section{LITERATURA CITADA}

ALMEIDA, J.H.S. Sistema de produção de melão cv. Valenciano Amarelo para o estado do Rio Grande do Norte. Mossoró: ESAM, 1992. $45 \mathrm{p}$. (Monografia graduação).

ANUÁRIO ESTATÍSTICO DO BRASIL. Rio de Janeiro: $I B G E$, v. 43/45, 1987/1994.

BLESDALE, J.K.A. Plant growth crop yield. Annals Applied Biology, v. 57, p. 173-182, 1969.

BRINEN, G.H.; LOCASCIO, S.J.; ELMSTROM, G.W. Plant and row spacing, mulch, and fertilizer rate effects on watermelon production. Journal of the American Society for Horticultural Science, v. 104, p. 724-726, 1979.

Tabela 3. Classificação percentual dos frutos de acordo com o tamanho, nas diferentes densidades de plantio para os híbridos Gold Mine, AF 646 e XPH 13096. Mossoró (RN), ESAM, 1996.

\begin{tabular}{|c|c|c|c|c|c|c|c|c|c|c|}
\hline \multirow{2}{*}{ Híbridos } & \multirow{2}{*}{$\begin{array}{c}\text { Densidade } \\
\text { PI/ha }\end{array}$} & \multicolumn{9}{|c|}{ TIPOS* } \\
\hline & & 05 & 06 & 07 & 08 & 09 & 10 & 11 & 12 & Granel \\
\hline \multirow{4}{*}{ Gold Mine } & 10.000 & 8,57 & 42,86 & 28,00 & 5,71 & 10,00 & & & 2,86 & 2,00 \\
\hline & 20.000 & & 27,96 & 36,56 & 15,05 & 10,72 & 3,22 & & 1,07 & 5,39 \\
\hline & 30.000 & 0,90 & 15,84 & 32,67 & 23,75 & 14,85 & 3,95 & 0,90 & 1,00 & 5,94 \\
\hline & 40.000 & 1,64 & 18,85 & 30,33 & 13,93 & 9,02 & 4,10 & 4,10 & 6,56 & 11,47 \\
\hline \multirow{4}{*}{ AF 646} & 10.000 & & 13,20 & 31,14 & 30,04 & 2,80 & 8,40 & 1,90 & 7,48 & 5,04 \\
\hline & 20.000 & & 6,38 & 25,05 & 23,41 & 4,74 & 11,07 & 4,00 & 13,11 & 12,14 \\
\hline & 30.000 & & 8,00 & 30,40 & 20,00 & 9,60 & 8,20 & 5,22 & 5,60 & 12,98 \\
\hline & 40.000 & & 3,50 & 14,82 & 15,27 & 19,08 & 14,50 & 3,82 & 9,92 & 15,20 \\
\hline \multirow{4}{*}{ XPH 13096} & 10.000 & 2,10 & 20,00 & 34,75 & 20,00 & 7,37 & 3,16 & 2,10 & 1,05 & 9,47 \\
\hline & 20.000 & 2,68 & 13,40 & 28,57 & 17,86 & 9,82 & 1,78 & 3,57 & 5,36 & 16,96 \\
\hline & 30.000 & 0,95 & 13,52 & 17,15 & 20,95 & 6,68 & 9,52 & 5,71 & 9,52 & 16,00 \\
\hline & 40.000 & & 6,50 & 25,00 & 12,46 & 7,43 & 8,60 & 13,04 & 6,96 & 20,00 \\
\hline
\end{tabular}

* Número de frutos por caixa de papelão com capacidade de $13 \mathrm{~kg}$. 
CANTLIFFE, D.J.; PHATAK, S.C. Plant population studies with pickling cucumbers grown for once-over harvest. Journal of the American Society for Horticultural Science, v. 100, n. 5, p. 464-66, 1975.

COSTA, N.D.; SOARES, J.M.; BRITO, L.T. de L.; FARIA, C.M.B. Doses de nitrogênio aplicadas via fertirrigação e densidade de plantio na cultura do melão. In: REUNIÃO BRASILEIRA DE FERTILIDADE DO SOLO E NUTRIÇÃO DE PLANTAS, 22, Manaus, 1996. Resumos. Manaus - AM, p. 196-7.

DAVIS, G.N.; MEINERT, U.G.H. The effect of plant spacing and fruit pruning on the fruits of P.M.R. No. 45 cantaloupe. Journal of the American Society for Horticultural Science, v. 87, p. 299-302, 1965.

FARIAS, J.R.B.; MARTINS, S.R.; FERNANDES, H.S. Comportamento do meloeiro cultivado em estufa plástica, em diferentes espaçamento e cobertura do solo. Horticultura brasileira, Brasília, v. 6, n. 1, p. 52, 1988.

GOMES, P.F. Curso de estatística experimental. São Paulo: Nobel, 1987, 430 p.

GRANBERRY, D.M.P.; COLDITZ; McLAURIN, W.J. Watermelon: comercial vegetable production. Univ. of Georgia, Athens, Coop. Ext. Serv. Circ. 466, 1986.
HOLLIDAY, R. Plant population and crop yield. Nature, v. 186, p. 22-24, 1969.

JANDEL SCIENTIFIC User's Manual. California: Jandel Scientific, 1991, 280 p.

KNAVEL, D.E. Growth, development, and yield potential of short internode muskmelon. Journal of the American Society for Horticultural Science, v. 113, p. 595-99, 1988.

MENDLINGER, S. Effect of increasing plant density and salinity on yield and fruit quality in muskmelon. Scientia Horticulturae, v. 57, p. 41-49, 1994.

NESMITH, D.S. Plant spacing influences watermelon yield and yield components. HortScience, v. 28, n. 9, p.885-887, 1993

NORUSIS, M.J. SPSS statistics. Illinois, SPSS Inc., $1990,320 \mathrm{p}$.

O' SULLIVAN, J. Irrigation, spacing and nitrogen effects on yield and quality of pickling cucumbers grown for mechanical harvesting. Canadian Journal Plant Science, v. 60, p. 92328, 1980.

PARIS, H.S.; NERSON, H.; BURGER, Y.; EDELSTEIN, M.; KARCHI, Z. Synchrony of yield of melons as affected by plant type and density. Journal of Horticultural Science, v .63 , n. 1, p. 141-47, 1988.
PARIS, H.S.; NERSON, H.; KARCHI, Z. Yield and quality of courgette as affected by plant density. Horticultural Abstracts, v. 56, n. 10, p. $836,1986$.

PATIL, C.B.; BHOSALE, R.J. Effect of nitrogen fertilization and spacings on the yield of watermelon. Indian Journal Agronomy, v. 21, p. 300-301, 1976.

PEDROSA, J.F. Cultura do melão. Mossoró: ESAM, 1997. 50 p. (Apostila).

PEDROSA, J.F.; TORRES FILHO, J.; MEDEIROS, I.B. de. Poda e densidade de plantio em melão. Horticultura brasileira, Brasília, v. 9, n. 1, p.18-20, 1991.

POWELL, C.A.; STOFFELLA, P.J.; PARIS, H.S. Plant population influence on squash yield, sweetpotato whitefly, and Zucchini yellow mosaic. Hortscience, v. 28, n. 8, p. 796-98, 1993

ROBINSON, R.W.; DECKER-WALTERS, D.S Cucurbits. New York: CAB Internacional, 1997. 226 p.

SCHALES, F.D.; TIMOTHY, J.N. Population density and mulch effects on muskmelon yields. HortScience, v. 23, n. 3, p.148, 1988.

WILLEY, R.W.; HEATH, S.B. The quantitative relationships between plant population crop yield. Advance Agronomy, v. 21, p. 281-321, 1969. 